\title{
PENGARUH MEDIA TUMBUH DAN CUKA ORGANIK PADA PERTUMBUHAN SEMAI PULAI (Alstonia scholaris)
}

\author{
The Influence of Growing Media and Organic Vinegar on the Growth of Pulai Seedlings (Alstonia \\ scholaris)
}

\author{
Yoseva Eva, Hanna Artuti Ekamawanti, Wiwik Ekyastuti \\ Fakultas Kehutanan Universitas Tanjungpura Pontianak. Jl. Daya Nasional Pontianak. \\ E-mail: yosevha11@gmail.com
}

\begin{abstract}
Pulai (Alstonia scholaris) is a local species and fast-growing plant that can be used in plantation development activities. The aim of this study was to obtain information on the growth and quality response of seedlings on growing media (a mixture of ultisol, cocopeat, chicken manure and husk charcoal) and organic vinegar (wood vinegar, peat vinegar and fern root vinegar). The research was carried out at the Kasa Rumah Pamer Room and Orchid Market Institute for Research and Service to the Tanjungpura University Community and at the Silviculture Laboratory of the Faculty of Forestry. This study uses an experimental method with split plot design with a completely randomized design (CRD) archetype. The treatment consisted of two factors, namely growth media (ultisol + cocopeat + chicken manure and ultisol + cocopeat + chicken manure + husk charcoal) as the main factor and organic vinegar (chemical fertilizer, peat vinegar, wood vinegar and fern root vinegar) as plot factor. The results showed that the mixed media of ultisol + cocopeat + chicken manure significantly affected the height of pulai seedlings by $55.4 \mathrm{~cm}$ (1.28 fold), $6.7 \mathrm{~mm}$ diameter (3.35 times) and number of seedling leaves 62, 25 (1.34 times) of planting media with rice husk charcoal. Organic vinegar has no significant effect on the growth and value of the quality of pulai seed quality index.
\end{abstract}

Keywords: growing media, organic vinegar, pulai seedlings

\section{PENDAHULUAN}

Menurut Mashudi et al. (2014), kebutuhan kayu untuk bahan baku industri dari tahun ke tahun semakin meningkat, sementara produksi kayu dari hutan alam cenderung menurun. Semakin menurunnya kemampuan produksi hutan alam untuk menyediakan bahan baku industri, pembangunan hutan tanaman dengan produktivitas tinggi merupakan salah satu alternatif yang dapat dilakukan untuk mengatasi permasalahan tersebut.
Oleh sebab itu bibit yang unggul dan berkualitas sangat diperlukan untuk mendukung pembangunan hutan tanaman dengan produktivitas tinggi. Pembangunan hutan tanaman biasa menggunakan jenis lokal dan tumbuh cepat serta mempunyai sebaran luas hampir di seluruh wilayah Indonesia. Salah satu jenis yang bisa digunakan dalam kegiatan pembangunan hutan tanaman yaitu pulai (Alstonia scholaris). 


\section{JURNAL HUTAN LESTARI (2019) \\ Vol. 7 (3) : 1007 - 1016}

Kualitas bibit tanaman sangat berpengaruh pada keberhasilan program pembangunan hutan tanaman dan rehabilitasi lahan bekas tebangan, karena bibit yang berkualitas akan menghasilkan tegakan dengan tingkat produktivitas tinggi. Bibit yang berkualitas harus didukung dengan media tumbuh yang baik dan pemberian pupuk. Selama ini media tumbuh yang digunakan adalah campuran tanah ultisol, cocopeat dan kotoran ayam seperti di Badan Pengelolaan Daerah Aliran Sungai dan Hutan Lindung (BPDASHL) Kapuas, sementara tanah ultisol dikenal sebagai tanah yang sifatnya memiliki kandungan bahan organik dan unsur hara yang sangat rendah. Oleh sebab itu untuk memerbaiki struktur dan unsur hara dari tanah tersebut selain ditambah cocopeat dan kotoran ayam diperlukan penambahan arang sekam.

Pemanfaatan bahan organik seperti cocopeat dan arang sekam padi sangat potensial digunakan sebagai campuran media tanam semai alternatif untuk mengurangi penggunaan tanah. Salah satu kelebihan penggunaan bahan organik sebagai media tanam semai adalah memiliki struktur yang dapat menjaga keseimbangan aerasi dan mempunyai sifat remah yang sangat penting bagi akar bibit tanaman (Putri 2008). Penambahan arang sekam pada media tanah dapat memperbaiki porositas media sehingga baik untuk respirasi akar, dapat mempertahankan kelembapan tanah serta dapat mengikat air untuk diserap oleh tanaman dan mendorong pertumbuhan mikroorganisme yang berguna bagi tanah dan tanaman (Kusmarwiyah dan Emi 2011). Selain itu, pemberian pupuk selama proses pemeliharaan bibit di persemaian juga sangat penting dilakukan untuk membantu meningkatan pertumbuhan dan kualitas bibit.

Pupuk yang umum digunakan saat ini terutama di BPDASHL Kapuas yaitu pupuk kimia (NPK). Sementara dalam proses pemeliharaan bibit tidak harus menggunakan pupuk kimia, karena selama ini pupuk kimia cenderung mahal. Oleh sebab itu, alternatif untuk mengurangi penggunaan pupuk kimia perlu dicari, yaitu menggunakan cuka organik sebagai sumber hara bagi tanaman. Cuka organik yang digunakan dalam penelitian ini yaitu cuka kayu, cuka gambut dan cuka akar pakis. Informasi tentang penggunaan cuka kayu, cuka gambut dan cuka akar pakis sebagai pupuk untuk pembibitan jenisjenis tanaman kehutanan saat ini masih sangat sedikit. Cuka kayu merupakan hasil samping pembuatan arang yang mengandung komponen kimia seperti asam asetat dan metanol yang berfungsi untuk mempercepat pertumbuhan tanaman (Komarayati et al. 2011). Penggunaan cuka gambut dan cuka akar pakis sebagai alternatif untuk mengurangi penggunaan pupuk kimia merupakan ide dari salah satu petani yang mengelola lahan gambut yang ada di Rasau Jaya. 
Berdasarkan uraian tersebut permasalahan yang ada dalam penelitian ini adalah apakah cuka organik dapat mendukung pertumbuhan dan kualitas bibit pulai terbaik pada media tumbuh semai. Oleh sebab itu diperlukan penelitian mengenai pengaruh pemberian cuka organik pada pertumbuhan dan kualitas bibit pulai pada media tumbuh campuran tanah ultisol, cocopeat, kotoran ayam dan arang sekam.

\section{METODE PENELITIAN}

Penelitian dilaksanakan di Rumah Kasa Ruang Pamer dan Pursa Angrek Lembaga Penelitian dan Pengabdian Kepada Masyarakat Universitas Tanjungpura dan di Laboratorium Silvikultur Fakultas Kehutanan dengan waktu penelitian selama kurang lebih 3 bulan. Metode yang digunakan dalam penelitian ini adalah metode eksperimen dengan pola split plot design rancangan dasar acak lengkap (RAL). Perlakuan yang ditempatkan sebagai petak utama, yaitu media tumbuh $(\mathrm{m})$ terdiri dari tanah ultisol + cocopeat + kotoran ayam $\left(\mathrm{m}_{1}\right)$ dan tanah ultisol + cocopeat + kotoran ayam + arang sekam $\left(\mathrm{m}_{2}\right)$. Sebagai anak petak, yaitu cuka organik $(\mathrm{n})$, terdiri dari pupuk kimia $\left(\mathrm{n}_{1}\right)$, cuka gambut $\left(\mathrm{n}_{2}\right)$, cuka kayu $\left(\mathrm{n}_{3}\right)$ dan cuka akar pakis $\left(\mathrm{n}_{4}\right)$.
Data utama dalam penelitian adalah pertambahan tinggi $(\mathrm{cm})$, pertambahan diameter (mm), jumlah daun (helai), persentase hidup tanaman (\%), bobot kering pucuk (g/tanaman), bobot kering akar (g/tanaman) dan indeks mutu bibit (IMB). Data penunjang adalah suhu udara $\left({ }^{\circ} \mathrm{C}\right)$ dan kelembapan (\%). Sebelum dianalisis ragam dilakukan uji asumsi kehomogenan menggunakan Uji Bartlett (Gaspersz 1991). Setelah diuji asumsi kehomogenan ragam dilanjutkan dengan analisis ragam, menggunakan rancangan petak terbagi dengan pola dasar RAL.

\section{HASIL DAN PEMBAHASAN}

\section{Pertumbuhan Semai Pulai yang} Diberi Cuka Organik pada Media Tumbuh

Hasil penelitian menunjukkan bahwa perlakuan cuka organik dan interaksi antara cuka organik dengan media tumbuh tidak mempengaruhi perbedaan pertumbuhan semai pulai. Sementara itu, perlakuan media berpengaruh sangaat nyata terhadap perbedaan pertumbuhan semai pulai. Rekapitulasi hasil penelitian yang telah dilakukan terhadap pertambahan tinggi, pertambahan diameter dan pertambahan jumlah daun yang diamati selama 12 minggu serta bobot kering akar dan bobot kering pucuk bibit pulai bisa dilihat pada Tabel 1. 
Tabel 1. Rekapitulasi hasil sidik ragam pengaruh media tumbuh dan cuka organik pada semai pulai selama 12 minggu setelah tanam (recapitulation of the results of the variance of the effect of growing media and organic vinegar on pulai seedlings for 12 weeks after planting)

\begin{tabular}{|c|c|c|c|c|c|}
\hline \multirow{2}{*}{$\begin{array}{c}\text { Sumber } \\
\text { keragaman }\end{array}$} & \multirow{2}{*}{$\begin{array}{l}\text { Tinggi } \\
(\mathrm{cm})\end{array}$} & \multirow{2}{*}{$\begin{array}{l}\text { Diameter } \\
(\mathbf{m m})\end{array}$} & \multirow{2}{*}{$\begin{array}{c}\text { Jumlah daun } \\
\text { (helai) }\end{array}$} & \multicolumn{2}{|c|}{ Bobot kering (g) } \\
\hline & & & & Akar & Pucuk \\
\hline Media (M) & $* *$ & $* *$ & $* *$ & tn & tn \\
\hline Cuka organik $(\mathrm{N})$ & tn & tn & tn & tn & $\operatorname{tn}$ \\
\hline Interaksi MN & tn & tn & tn & tn & tn \\
\hline
\end{tabular}

Tabel 1 menunjukkan bahwa pengaruh perlakuan cuka organik secara tunggal dan interaksinya dengan media tidak signifikan pada semua variabel yang diamati, yang berarti bahwa cuka organik belum memberikan pengaruh yang nyata pada pertumbuhan semai pulai selama 12 minggu setelah tanam. Penggunaan cuka organik $4 \%$ pada penelitian ini belum efektif untuk menunjang pertumbuhan semai pulai, baik pada media campuran tanah ultisol + cocopeat + kotoran ayam maupun media campuran tanah ultisol + cocopeat + kotoran ayam + arang sekam. Selain itu, kemungkinan konsentrasi cuka organik yang diperlukan untuk dapat meningkatkan pertumbuhan semai pulai yaitu di bawah atau di atas 4\%. Menurut Komarayati et al. (2013) apabila konsentrasi cuka kayu ditingkatkan dari $3 \%$ ke $4 \%$ maka dapat memberikan kecenderungan penurunan pertumbuhan bagi tanaman sengon karena komponen kimia pada konsentrasi cuka kayu yang tinggi justru dapat menjadi racun bagi tanaman. Hal ini berbeda dari hasil penelitian Komarayati dan Santoso (2011) yang menyatakan bahwa pemberian cuka organik terutama cuka kayu sebesar 2\% sudah dapat meningkatkan pertumbuhan anakan mengkudu, yakni peningkatan pertambahan tinggi sebesar 2,72 kali; diameter 3,00 kali; panjang daun 2,13 kali dan lebar daun 1,40 kali. Hasil penelitian Komarayati dan Pari (2014) juga menyebutkan bahwa cuka kayu dengan konsentrasi $2 \%$ dapat meningkatkan rata-rata pertambahan tinggi anakan sengon tertinggi $(156,33$ $\mathrm{cm})$ dan terendah dengan cuka kayu $4 \%$ $(75,68 \mathrm{~cm})$.

Penelitian ini terdapat kesalahan aplikasi dalam hal pemberian cuka organik dimana pada saat penyemprotan tidak dihitung secara pasti berapa kali menyeprot dengan alat semprot, sehingga kemungkinan terjadi bias antara perlakuan satu dengan perlakuan lainnya sekitar 0-1 cc. Meskipun biasnya sangat kecil, kesalahan tersebut diduga dapat mempengaruhi hasil penelitian. Selain itu faktor lingkungan seperti suhu dan kelembapan udara juga dapat mempengaruhi pertumbuhan semai pulai. Suhu udara rata-rata selama penelitian tiga bulan berkisar antara $28,5^{\circ} \mathrm{C}-30,12^{\circ} \mathrm{C}$ dan rata-rata 
kelembapan udara berkisar antara $65,65 \%-69,39 \%$. Menurut Istomo dan Valentino (2012) suhu yang baik untuk perkembangan akar dan tunas hampir semua jenis tanaman adalah $21^{\circ} \mathrm{C}$ $27^{\circ} \mathrm{C}$, sedangkan Kelembaban udara mendekati $100 \%$.

Berdasarkan perhitungan data pertumbuhan semai pulai yang diamati selama 12 minggu, terlihat bahwa hasil penggunaan cuka organik tidak berbeda dengan perlakuan yang diberi pupuk NPK walaupun tidak berpengaruh nyata pada semua variabel yang diamati. Perlakuan yang diberi cuka organik baik pada media campuran tanah ultisol + cocopeat + kotoran ayam maupun media campuran tanah ultisol + cocopeat + kotoran ayam + arang sekam dalam hal ini justru dapat meningkatkan pertumbuhan semai pulai jika dilihat dari nilai rerata semua variabel yang diamati.

Hasil analisis ragam menunjukkan bahwa media yang digunakan memberikan pengaruh yang sangat nyata pada pertambahan tinggi, diameter dan jumlah daun. Namun tidak berpengaruh nyata terhadap bobot kering akar dan bobot kering pucuk bibit pulai. Oleh karena itu maka dilakukan uji lanjut dengan uji beda nyata jujur (BNJ) yang hasilnya dapat dilihat pada Tabel 2.

Tabel 2. Rerata pertumbuhan semai pulai pada media tanam selama 12 minggu setelah tanam (the average growth of pulai seedlings in the planting medium for 12 weeks after planting)

\begin{tabular}{cccc}
\hline Perlakuan & $\begin{array}{c}\text { Rerata } \\
\text { Pertambahan } \\
\text { tinggi }(\mathbf{c m})\end{array}$ & $\begin{array}{c}\text { Rerata } \\
\text { Pertambahan } \\
\text { Diameter }(\mathbf{m m})\end{array}$ & $\begin{array}{c}\text { Rerata Pertambahan } \\
\text { Jumlah Daun (helai) }\end{array}$ \\
\hline $\mathrm{M}_{1}$ & $55,4 \mathrm{~b}$ & $6,7 \mathrm{~b}$ & $62,25 \mathrm{~b}$ \\
$\mathrm{M}_{2}$ & $43,2 \mathrm{a}$ & $2 \mathrm{a}$ & $46,5 \mathrm{a}$ \\
\hline
\end{tabular}

Keterangan: rerata yang diikuti dengan notasi huruf kecil yang sama (a) berarti tidak signifikan, sedangkan (b) berarti signifikan atau berbeda nyata pada uji BNJ taraf 5\%

Berdasarkan hasil analisis beda nyata jujur terlihat bahwa perlakuan media campuran tanah ultisol + cocopeat + kotoran ayam signifikan dengan pertambahan tinggi, diameter dan jumlah daun yang diberi perlakuan tanah ultisol + cocopeat + kotoran ayam + arang sekam. Hal ini berarti bahwa media campuran tanah ultisol + cocopeat + kotoran ayam mampu meningkatkan pertambahan tinggi bibit pulai sebesar 55,4 cm (1,28 kali lipat), diameter 6,7 $\mathrm{mm}(3,35$ kali lipat $)$ dan jumlah daun bibit 62,25 (1,34 kali lipat) dari media tanam dengan arang sekam. Sejalan dengan penelitian Lukman et al. (2012) bahwa pupuk kandang ayam mengandung $\mathrm{pH}$ 7,1-Netral dan Corganik $17.61 \%$ sangat tinggi yang berarti bahwa kotoran ayam dapat digunakan sebagai pupuk organik penyubur tanah. Pemberian pupuk kandang juga dapat memperbaiki sifatsifat fisik tanah seperti permeabilitas 
tanah, struktur tanah, daya menahan air dan kation-kation tanah. Didukung hasil penelitian Ansoruddin et al. (2017) bahwa pemberian pupuk kandang ayam berpengaruh sangat nyata pada pertambahan tinggi bibit gaharu. Hasil penelitian Riana et al. (2017) juga menunjukkan bahwa pertumbuhan diameter dengan perlakuan pemberian cocopeat dan kotoran ayam berpengaruh sangat nyata dibandingkan dengan tanpa cocopeat dan kotoran ayam. Selain itu juga terlihat bahwa perlakuan yang terbaik untuk pertumbuhan diameter adalah campuran cocopeat sebanyak $50 \mathrm{~g}$ dengan kotoran ayam $50 \mathrm{~g}$ (1:1). Seiring dengan pertumbuhan tinggi dan diameter, semai pulai pada penelitian ini juga mengalami pertambahan jumlah daun. Hal ini diduga karena adanya pertumbuhan berupa pertambahan tinggi, sehingga bertambahnya bukubuku batang tempat terbentuknya daun. Hal ini senada dengan pendapat Ramadhan et al. (2018) bahwa pembentukan daun berhubungan erat dengan peningkatan tinggi bibit. Daun terbentuk pada buku-buku batang sehingga meningkatnya tinggi bibit juga diikuti bertambahnya jumlah daun.

Menurut Irawan et al. (2014) media cocopeat memiliki kelebihan sebagai media tanam dikarenakan karakteristiknya yang mampu mengikat dan menyimpan air dengan kuat, serta mengandung unsur-unsur hara esensial seperti kalsium $(\mathrm{Ca})$, magnesium $(\mathrm{Mg})$, kalium $(\mathrm{K})$, natrium $(\mathrm{N})$, dan fosfor $(\mathrm{P})$.
Didukung hasil penelitian Ramadhan $e t$ al. (2018) bahwa penggunaan cocopeat $25 \%$ dan $50 \%$ yang dikombinasikan dengan tanah pada media tumbuh merupakan komposisi yang paling baik karena berpengaruh baik terhadap tinggi, diameter dan jumlah daun bibit sengon laut.

Selain menunjukkan pengaruh yang signifikan dari media campuran tanah ultisol + cocopeat + kotoran ayam terhadap pertumbuhan tinggi, diameter dan jumlah daun, ternyata hasil penelitian ini juga menunjukkan bahwa kedua campuran media yang digunakan tidak berpengaruh nyata terhadap bobot kering akar dan bobot kering pucuk semai pulai. Hal ini berkaitan dengan pendapat Prananda et al. (2014) bahwa media penyapihan sebagai tempat perkembangan akar merupakan salah satu faktor lingkungan yang mempengaruhi pertumbuhan bibit, media penyapihan yang baik harus memiliki persyaratan antara lain mampu menjaga kelembapan, memiliki aerasi dan drainase yang baik, tidak memiliki salinitas yang tinggi serta bebas dari hama dan penyakit. Selain itu pembentukan akar pada bibit tingkat keberhasilannya lebih ditentukan oleh sifat fisik media dibandingkan dengan sifat kimia yang terkandung dalam media, karena sifat fisik ini berkenaan dengan ketersediaan air dan adanya kelancaran sirkulasi udara dalam media yang dibutuhkan bibit dalam proses pembentukan akar. Di samping itu ukuran polybag yang kurang besar bisa 
membuat akar tidak mampu berkembang dengan baik.

\section{Indeks Mutu Bibit Pulai}

Berdasarkan data bobot kering pucuk, bobot kering akar, tinggi dan diameter bibit pulai maka didapat hasil perhitungan nilai indeks mutu bibit. Rerata indeks mutu bibit pulai dari setiap perlakuan dapat dilihat pada Tabel 3.

Tabel 3. Pengaruh media dan cuka organik pada indeks mutu bibit pulai (the influence of media and organic vinegar on the quality index of pulai seeds)

\begin{tabular}{ccccc}
\hline \multirow{2}{*}{ Media } & \multicolumn{4}{c}{ Cuka organik } \\
\cline { 2 - 5 } & $\begin{array}{c}\text { Tanpa cuka } \\
\text { organik } \\
\text { (NPK) }\end{array}$ & $\begin{array}{c}\text { Cuka } \\
\text { gambut }\end{array}$ & $\begin{array}{c}\text { Cuka } \\
\text { kayu }\end{array}$ & $\begin{array}{c}\text { Cuka akar } \\
\text { pakis }\end{array}$ \\
\hline $\begin{array}{c}\text { ultisol + cocopeat + kotoran } \\
\text { ayam }\end{array}$ & 0,07 & 0,39 & 0,13 & 0,22 \\
$\begin{array}{c}\text { ultisol + cocopeat }+ \text { kotoran } \\
\text { ayam + arang sekam }\end{array}$ & 0,04 & 0,14 & 0,14 & 0,17 \\
\hline
\end{tabular}

Nilai IMB diperoleh dari parameter pertumbuhan tinggi, diameter, bobot kering pucuk dan bobot kering akar. IMB digunakan untuk mengetahui kualitas semai dari kemampuan adaptasinya terhadap lingkungan (Wasis et al. 2015). Menurut Lackey dan Alm (1982) dalam Rahayu dan Wahyuni (2016), IMB minimal bibit agar dapat bertahan hidup yaitu sebesar 0,09. Tabel 3 menunjukkan bahwa nilai indeks mutu bibit pada setiap perlakuan telah melebihi standar mutu bibit kecuali pada perlakuan yang diberi pupuk NPK baik pada media campuran tanah ultisol + cocopeat + kotoran ayam maupun media campuran tanah ultisol + cocopeat + kotoran ayam + arang sekam. Hal ini berarti bahwa walaupun cuka organik sebesar $4 \%$ belum mampu meningkatkan pertumbuhan bibit pulai selama 12 minggu, tetapi sudah mampu meningkatkan kualitas mutu bibit dan jika ditinjau dari nilai indeks mutu bibitnya bibit tersebut akan mampu bertahan hidup jika ditanam dilapangan. Perlakuan yang memiliki nilai rerata indeks mutu bibit tertinggi $(0,39)$ yaitu perlakuan yang diberi cuka gambut pada media tanah ultisol + cocopeat + kotoran ayam.

Nilai IMB pada penelitian ini terutama pada perlakuan yang diberi cuka organik baik pada media campuran tanah ultisol + cocopeat + kotoran ayam maupun media campuran tanah ultisol + cocopeat + kotoran ayam + arang sekam telah memenuhi standar minimal bibit bisa ditanam di lapangan, akan tetapi nilai bobot kering pucuk dan bobot kering akar berdasarkan perhitungan statistiknya tidak signifikan. Hal ini berarti bahwa jika dilihat dari nilai bobot kering pucuk dan bobot kering akarnya belum 
menunjukkan kesiapan bibit di lapangan.

\section{Potensi Cuka Organik}

Analisis ragam menunjukkan bahwa pengaruh cuka organik dan pupuk kimia tidak signifikan pada pertumbuhan awal bibit pulai. Namun cuka organik memiliki potensi dalam meningkatkan nilai IMB pulai. Hasil penelitian juga memperlihatkan bahwa perlakuan cuka gambut baik pada media campuran tanah ultisol + cocopeat + kotoran ayam maupun media campuran tanah ultisol + cocopeat + kotoran ayam + arang sekam merupakan perlakuan terbaik yang memberikan rerata tertinggi semai pulai pada semua variabel yang diamati selama 12 minggu. Hal ini berarti bahwa cuka organik mampu memberikan potensi untuk mendukung pertumbuhan semai pulai.

Menurut Komarayati et al. (2011) cuka organik terutama cuka kayu yang terkandung dalam asap hasil pembakaran arang kayu berguna untuk memperbaiki mutu tanah dan membantu pertumbuhan tanaman agar lebih baik. Komponen kimia cuka kayu seperti asam asetat, metanol dan fenol masingmasing mempunyai fungsi dan manfaat bagi tanaman. Asam asetat berfungsi untuk mempercepat pertumbuhan dan mencegah penyakit tanaman. Metanol berfungsi untuk mempercepat pertumbuhan tanaman. Fenol berfungsi untuk mencegah serangan hama dan penyakit tanaman. Selain itu berdasarkan hasil analisis, kandungan unsur hara makro pada cuka organik terdiri dari $\mathrm{C}$ organik $(6,12 \%-7,35 \%)$; $\mathrm{N}$ total $(0,62 \%-0,67 \%) ; \mathrm{P}_{2} \mathrm{O}_{5}$ total $(0,24 \%-0,312 \%)$ dan $\mathrm{K}_{2} \mathrm{O}$ total $(0,31 \%$ - 0,36\%). Jika dilihat dari kandungan unsur hara yang terkandung di dalamnya, cuka organik telah memenuhi persyaratan minimal agar dapat dijadikan sebagai pupuk cair organik dan layak untuk diuji coba pada tanaman. Namun demikian, cuka kayu yang disiramkan dalam tanah tidak dapat bertahan lama, karena akan menguap. Berbeda dengan bahan organik seperti cocopeat yang akan tetap berada dalam tanah dan resisten sampai waktu yang lama. Hal ini didukung hasil penelitian Komarayati et al. (2014) bahwa pemberian cuka organik pada anakan jabon berpengaruh nyata terhadap pertambahan tinggi dan diameter. Pemberian cuka organik 4\% menghasilkan rata-rata pertambahan tinggi anakan gaharu yang tertinggi yaitu $72,20 \mathrm{~cm}$. Selain itu menurut hasil penelitian Siarudin dan Suhaendah (2007), cuka organik dapat meningkatkan pertumbuhan dan riap tinggi anakan sengon sebesar 75,48 cm dan 66,62 $\mathrm{cm}$ selama tiga bulan penelitian dibandingkan dengan anakan tanpa perlakuan yang memiliki pertumbuhan tinggi dan riap lebih rendah.

Berdasarkan hasil penelitian ini menunjukkan bahwa cuka organik memiliki potensi untuk meningkatkan kualitas semai pulai. Namun potensi ini masih perlu dikembangkan lagi dalam 
penelitian berikutnya untuk mengetahui konsentrasi cuka organik yang paling efektif apakah di bawah atau di atas $4 \%$.

\section{KESIMPULAN}

Berdasarkan hasil penelitian dapat diambil kesimpulan bahwa media yang baik untuk pertumbuhan bibit pulai yaitu media campuran tanah ultisol + cocopeat + kotoran ayam dengan perbandingan 3:1:1. Selain itu, cuka organik mampu meningkatkan indeks mutu bibit pada semai pulai baik pada media campuran tanah ultisol + cocopeat + kotoran ayam maupun media campuran tanah ultisol + cocopeat + kotoran ayam + arang sekam. Alternatif pemupukan dapat menggunakan cuka organik yang memiliki kemampuan yang sama dengan pupuk NPK dalam mendukung pertumbuhan bibit pulai.

\section{SARAN}

Penelitian selanjutnya disarankan untuk mengubah perbandingan media campuran tanah ultisol + cocopeat + kotoran ayam dan mencoba menggunakan cuka organik dengan konsentrasi di bawah ataupun di atas 4\%. Diharapkan dari penelitian ini dapat diperoleh pengetahuan baru mengenai jenis pupuk organik yang baik bagi pertumbuhan tanaman tanpa harus menggunakan pupuk kimia.

\section{DAFTAR PUSTAKA}

Ansoruddin, Batubara LR, Simatupang HS. 2017. Respon pemberian pupuk kandang ayam dan pupuk sp36 terhadap pertumbuhan bibit tanaman gaharu (Aquilaria malaccensis). Jurnal Penelitian Pertanian BERNAS 13(1): 1-7.

Gaspersz V. 1991. Metode Perancangan Percobaan. Bandung:CV Armico.

Irawan A, Hidayah HN. 2014. Kesesuaian penggunaan cocopeat sebagai media sapih pada politube dalam pembibitan cempaka (Magnolia elegans). Jurnal Wasian 1(2): 73-76.

Istomo, Valentino N. 2012. Pengaruh perlakuan kombinasi media terhadap pertumbuhan anakan tumih (Combretocarpus rotundatus (Miq.) Danser). Jurnal Silvikultur Tropika 3(2): 81-84.

Komarayati S, Gusmailina, Pari G. 2011. Produksi cuka kayu hasil modifikasi tungku arang terpadu. Jurnal Penelitian Hasil Hutan 29(3): 234-247.

Komarayati S, Gusmailina, Pari G. 2013.Arang dan cuka kayu produk hasil hutan bukan kayu untuk meningkatkan pertumbuhan tanaman dan serapan hara karbon. Jurnal Penelitian Hasil Hutan 31(1): 49-62.

Komarayati S, Gusmailina, Pari G. 2014. Pengaruh arang dan cuka kayu terhadap peningkatan pertumbuhan dan simpanan karbon. Jurnal Penelitian Hasil Hutan 32(4): 313-328.

Komarayati S, Pari G. 2014. Kombinasi pemberian arang hayati dan cuka kayu terhadap pertumbuhan jabon dan sengon. Jurnal Penelitian Hasil Hutan 32(1): 12-20.

Kusmarwiyah R, Emi S. 2011. Pengaruh media tumbuh dan pupuk organik cair terhadap 
pertumbuhan dan hasil tanaman seledri (Apium graveolens L.). Crop Agro 4(2): 7-12.

Lukman AH, Sofyan A, Muslimin I. 2012. Pengaruh penyiangan dan pemupukan terhadap pertumbuhan awal tanaman pulai (Alstonia scholaris R. Br). Jurnal Penelitian Hutan Tanaman 9(1): 1-8.

Mashudi, Adinugraha HA, Yuskianti V. 2014. Budidaya pulai (Alstonia spp.) untuk bahan barang kerajinan. Bogor: IPB Press.

Putri AI. 2008. Pengaruh media organik terhadap indeks mutu bibit cendana (Santalum album). Jurnal Pemuliaan Tanaman Hutan 21(1):1-8.

Prananda R, Indriyanto, Riniarti M. 2014. Respon pertumbuhan bibit jabon (Anthocephalus cadamba) dengan pemberian kompos kotoran sapi pada media penyapihan. Jurnal Sylva Lestari 2(3):29-38.

Rahayu AAD, Wahyuni R. 2016. Pengaruh media organik sebagai media sapih terhadap kualitas bibit bidara laut (Strychnos lucida
R. Brown). Jurnal Pemuliaan

Tanaman Hutan 10(1):13-22.

Ramadhan D, Riniarti M, Santoso T. 2018. Pemanfaatan cocopeat sebagai media tumbuh sengon laut (Paraserianthes falcataria) dan merbau darat (Intsia palembanica). Jurnal Sylva Lestari 6(2): 22-31.

Riana A, Muin A, Fahrizal. 2017. Penggunaan campuran cocopeat dan pupuk kandang untuk penanaman gaharu (Aquilaria spp) pada tanah ultisol di Desa Pak Laheng Kecamatan Toho. Jurnal Hutan Lestari 5(4): 962951.

Siarudin M, Suhaendah E. 2007. Uji pengaruh mikoriza dan cuka kayu terhadap pertumbuhan lima provenan sengon di persemaian. Jurnal Pemuliaan Tanaman Hutan 1(1): 1-4.

Wasis B, Mulyana D, Winata B. 2015. Pertumbuhan semai jabon (Anthocephalus cadamba) pada media bekas tambang pasir dengan penambahan sub soil dan arang tempurung kelapa. Jurnal Silvikultur Tropika 6(2): 93-100. 